\title{
Salary and Tenure of Catalogers
}

$\mathrm{I}^{\mathrm{N}}$ ANOTHER era the encyclopedists made knowledge available through synthesis; in this day the opportunity to serve society in a similar manner is open to no group in greater measure than to librarians. The unique contribution of the librarian to the group or to the individual is his knowledge of books. How and what to buy for a book collection, how to organize and catalog the collection, and how to draw from the collection whatever is required at a particular time for a particular purpose is the expert application of that many-faceted knowledge of books.

With such a viewpoint of librarianship, the collection of facts regarding the contemporary status of the cataloger/classifier, one variety of the genus librarian, has significance only as an indication of the possibility under these conditions of working and living for the cataloger/classifier to make his contribution adequate to the needs of the institution and community as well as to grow and develop in personal wisdom.

In order to attract the person interested in and devoted to a life and career among books (using books as the name for all kinds of records of the thinking of men) it should be possible to present a picture of the pattern of such a life. That picture may exist in the minds of librarians who have had contact with people in those positions in a variety of libraries over a period of years. An assemblage of the facts are, however, unavailable to the young student searching for his niche.

\footnotetext{
1 Paper presented at the meeting of the Division of Cataloging and Classification, American Library Association, San Francisco, July r, 1947.
}

In order to remedy this lack in part, a series of questions was prepared by a graduate seminar at the University of Chicago in the winter of 1945-46. The group included a cataloger from a progressive medium-sized public library in the Middle West, two university library assistants, one of whom was a cataloger from an eastern college, the other a classifier from a Pacific coast university, and finally a young library administrator. Their selection of the facts to be secured, their recognition of the limits of information likely to be available as well as the limits of time and interest of those who would answer the questions, and their phrasing and rephrasing of the questions themselves is responsible for the primary value of the questionnaire. Helpful criticism came from several cataloger-administrators when a preliminary draft was ready; interest from A.L.A. Headquarters staff; and, ultimately, sponsorship of the questionnaire by the division's Special Committee on Recruiting contributed in no small way to the furtherance of the study. Head catalogers were addressed in the hope that their vital concern for the information would bring a full response. The belief seems to be warranted by the return of 133 answers, which is slightly better than 60 per cent of the 209 questionnaires sent out.

Since there is no list of catalogers later than Lucile M. Morsch's compilation of I937 available, the secretaries of the regional groups were asked for lists of members of the groups. Prompt and gracious cooperation came from the groups although 
the lists themselves proved in some cases to be somewhat informal, and a further checking against the A.L.A. Handbook was made in the endeavor to address head catalogers only-and at their latest addresses. The 209 names are those of heads of catalog departments who are members of A.L.A. and members of regional groups. This sample, we may assume, represents the most alert and professional interest among catalogers. It is also representative of twenty of the states plus the District of Columbia and the Province of British Columbia. Each section of the country is represented although several Middle Western states where librarians are active are strangely absent. Kinds and sizes of libraries include university, college, special (these last were usually of reference and research nature and were grouped with the college and university libraries in the analysis) and public libraries-all in proportions which resemble the distribution of those libraries throughout the country.

\section{No Need for Larger Sampling}

A preliminary analysis of the first 80 per cent of the returns was made, and as this showed little variation from the final analysis of the I IO usable answers, it is fair to assume that a larger sample would add little to the range of information secured or would change the results in no significant fashion. The majority of the answers are concerned with comparatively small departments-also representative of the total picture of library cataloging throughout the whole country and an aspect which sometimes seems neglected in discussions of cataloging problems per se. Differences in departmental organization, allocation of duties, and problems of special types of book collections (although neither questioners nor answerers were unaware of these) were not considered in the study. They are a part of the pattern to be presented to the possible recruit undoubtedly but more is available in print on that subject than on the more economic aspects of the cataloger/classifier which constitute the present concern.

Size of library in the analysis was measured in terms of volumes as reported in the American Library Directory of 1945-not too far removed from October 1946 when this information was secured. Large libraries are those over $1,000,000$ volumes. Three in the university group and four in the public are found here. Medium-large represents the 500,000 to $1,000,000$ group with 8 university libraries and 7 public libraries reporting. Medium libraries are I00,000 to 500,000 volumes with 32 college and university libraries and $2 \mathrm{I}$ public libraries. The smallest size is of libraries under I0o,00o volumes (meaning as low as 20,000 ) with 23 colleges and 12 public libraries. A fair balance of kinds of libraries occurs in each size group and the samples' totals of the various size groups may well be representative of the whole totals.

\section{Salaries}

Recalling that the A.L.A. Board on Personnel Administration in its "Salary Policy Statement" published in the Oct. I, 1946 Bulletin, p. 29I-92, recommended a minimum or base salary of $\$ 2100$ for a beginning position in the professional service, it is somewhat disconcerting to find (in that same month) that the minimum salaries reported for head catalogers (who are almost never beginners) was $\$ 1500-\$ 2200$ for public libraries in the two smaller brackets and $\$ 1450-\$ 1800$ for colleges libraries in the same brackets. Minimums in the 500,000 to $1,000,000-v 0 l u m e$ libraries are $\$ 2700$ in public and \$3000 in college and university libraries. Maximums for these same brackets are: 
$\$ 2460$ - small public

\$3924-100,000-500,000 public

$\$ 4500-500,000$ to $\mathrm{I}, 000,000$ public

$\$ 3350-$ small college

\$4902-100,000-500,000 college

$\$ 5905-500,000$ to $\mathrm{I}, 000,000$ university

Since some questionnaires omitted salaries, as institutions sometimes hold that as confidential information, the salary ranges may not be complete, but since only a few omitted answering this question the smaller number probably does not perceptibly skew the truth. With the sole exception of the low minimum of $\$ 1200$ appearing in the I00,000-500,000-volume public library the salaries progress with the size of the library. Maximums in the group report often overlap minimums of the next higher group. Government libraries which appear in the university group usually account for the highest salaries. This we know to be particularly true in the last few years.

Assistant catalogers' salaries are not reported for the smallest public libraries but for the two middle groups the salaries range from $\$ 1470$ to $\$ 3120$ and $\$ 1800$ to $\$ 3360$. In the college and university categories the smallest libraries pay assistants' salaries of $\$ 1200$ to $\$ 3350$, the 100,000 to $500,000-$ volume library pays $\$ 1675$ to $\$ 3397$ and the 500,000 to I,000,000-volume library pays $\$ 1800$ to $\$ 4902$.

\section{Longest Service, Largest Salary?}

The relation of length of tenure to salary requires a more meticulous analysis than is easy to report orally, but it can be said that a long service is not always accompanied by the largest salary. On the other hand the large salary does sometimes accompany the long years and up to a certain point a positive correlation of the two factors might be discovered. But as Joseph L. Wheeler once pointed out, it is often the willingness to move which raises salaries. A nice discussion (though endless) could be started on the question of the value of continuity versus mobility in a professional cataloging career. That head catalogers do not move from one library to another with any great frequency must be the conclusion drawn from the number of years reports as "in this position" by the head catalogers. The longest tenure reported is thirty-three years. There are, of course, instances of head catalogerships vacant or held from one to three years by the present incumbent, but the usual report is of an incumbency of between ten and twenty years.

First assistants in the larger libraries do not move much more than their chiefs, although there are fewer first assistants in our total picture and their less impressive total of years in office therefore shows them as a class more like the "senior catalogers" than like their chiefs. This fact of long tenure in the position of head cataloger, while advantageous to the institution and not unnatural for the individual who reaches that stage after the years when change of place and work loom as attractive may account in some measure for the static quality of salaries. What administrator is going out of his way to boost the wages of the good service he is sure of? The laws of need apply here with telling force. So the head cataloger, desiring a permanent home, understanding better than any one else on the staff, probably, the values which accrue to the expeditious handling of her work from experience in the particular situation, must seek other levers to keep her salary in line with that of other administrative officers and to insure adequate compensation to those positions which are necessarily subordinate to hers. (I think the feminine pronoun can still be used with truth.)

Salary schedules or classification and pay plans are found consistently throughout all brackets of public libraries more frequently than in college and university libraries. Only one plan was found among the 23 
smallest college libraries while 7 of the 12 small public libraries reported plans. It is also in the public library group that plans are reported under consideration by libraries not now adhering to them. Regular review of salaries also seems to be more prevalent in public libraries than in college libraries. It was in response to the question on regular review of salaries that those answering the questionnaire resorted frequently to comment: as "NO" in capitals, or a despairing sounding "I often think not." One public library in the 500,000 to $\mathrm{I}, \mathrm{OOO}, \mathrm{OOO}$ bracket made the sole report that the pay classification plan was based on a job analysis. Possibly more might have reported similarly had the specific question been asked. The largest libraries in both groups unanimously report classification plans.

There is variation in hours worked per week : 36 to 44 hours is the complete range, both extremes being found in the college and university group, with only one instance of the low 36 hours and three of the 44 hours. Almost half of all the libraries reported a 40 -hour week, and just as many under 40 , the small fraction remaining were over 40 hours. Much greater variation is found in vacation provisions. Many versions of a month in terms of days ( 26 days being the most frequently named) is the usual vacation in the college and university library and in the larger public library. The public library up to 500,000 volumes reports a twoweek vacation as often as a month vacation. The smaller college library by contrast mentions school holidays and even summer closing of two and three months (usually unpaid in the last instance). Unpaid leaves of absence for study purposes may be arranged in all types of libraries, but the sabbatical for librarians is practically unheard of. Allowance of time for attending professional meetings is often mentioned.
Allowance of time for illness is entirely unstandardized. Indefinite arrangements, sliding scales depending on merit of individual cases, 6 days to I 50, are the extreme and no control tendency discernible.

\section{Agreement on Initial Requisites}

There is almost unanimous agreement on college degree, library school degree, and experience as requisites for initial appointment. Apparently experience must be gained as junior catalogers in the larger libraries. This may point to a need for consideration of these agencies as postgraduate training schools or as internship experience. Perhaps a question may be raised regarding the rigid enforcement of the requirements claimed-they may have been named as desirable requirements.

The gentleman's agreement seems to be the prevailing basis for library employment. Only a scattering of civil service and annual contracts appear in the reports. The prevalence of a three- or six-month probationary period and one year and three year probations (among the college and university libraries) may be a surprising fact. I am even tempted to question whether this probationary period is made known to the candidate for a position although it may be a clearly-held reservation in the employer's mind. Indefinite tenure is clearly the very general practice as is also the absence of any system of rating the merit of work.

The report of a retirement policy is nearly unanimous. The questionnaire did not call for an explicit statement of age or retirement but some volunteered 65 and some 70 as the age of retirement from that library. One statement of a retirement policy as optional gave some cause for meditation. Pension systems or insurance provisions to which both the institution and the individual contribute are almost universal. Four college libraries reported institutionally supported pensions and one 
public library an endowed pension fund.

Staff associations are so infrequent that they may be considered rare with the exception of the public library of from 500,000 to I,O0o,ooo volumes. All of the libraries in this group reported staff associations.

\section{Need for Interviews}

Reasons for change of position as listed do not, I feel, get at the real motives, for the most frequently named reason is "To another position." That this involved better salary, dissatisfaction with the kind of work, or even such factors as housing could be established by interview and a study of catalogers' attitudes (such as that being made for nurses by the U.S. Bureau of Labor statistics). "Marriage," and "transfer to another department" are named any number of times as reasons for leaving cataloging positions. Once this transfer of departments was specified as promotion to head librarianship (since no succeeding librarian had been appointed in this case, doubtless the transfer simply meant additional duties). A variety of reasons appeared in individual cases, the total of death, babies, Army, Navy, Red Cross, school, home, unsatisfactory work, and "temperamental maladjustment" approximately equalling the category of transfer to another department. I suspect the value of a statistical count of these answers as it was apparent that clerical and subprofessional changes had been included in the answers. A more truly definitive study is needed on this point.

Is there, in this maze, a pattern to hold up for a student's inspection? Here is a career with well-defined educational qualifications required, plus an almost unlimited variety of qualities that can prove useful, which may best be entered as an assistant, salary still \$1450-\$1800, where one may continue from two to nine and even twentynine years, possibly advancing or moving to senior assistantships and then to first assistantships or to headships of smaller libraries, and, finally, in a few cases, to headships of large library departments with a possible maximum of $\$ 8059$, but more frequently a maximum between $\$ 4000$ and \$5000. The larger library usually pays the larger salary. Co-workers and chiefs are likely to remain with one in the department or library for considerable periods or years.

\section{How Recruit?}

There is more likelihood of classification and pay schedules in public than in academic libraries but more variation in vacations and holidays in the academic than in the public libraries. Finally, though this has little interest for the beginner, there will be a pension plan which will provide a basis for support upon retirement. Can these bare facts entice the recruit? Not alone; possibly alone, they repel. Fortunately or unfortunately they do not stand alone and as I read the few comments contributed in the inevitable space for comment on any questionnaire, catalogers still stand in dire need for the dispelling of the myth and attitude that they and their work are dry, dull, and demanding. Just now it is fashionable to lay many of the ills of the library profession at the door of the library school.

I am inclined to believe that we would find, as did the nurses, that the personal influence and enthusiasm of some member of the profession is the most deciding cause in the choice of a profession by a young beginner. It behooves us individually to avoid becoming "Cassandras" if we would attract competent assistants in adequate numbers to carry on the leadership and the profession. 